\title{
RELECTURAS E INTERVENCIONES «FEMENINAS»/ FEMINISTAS EN LA REVISTA LA LITERATURA ARGENTINA
}

\author{
«FEMININE»/FEMINIST RE-READINGS AND \\ INTERVENTIONS IN LA LITERATURA ARGENTINA \\ MAGAZINE
}

Laura CABEZAS

Author / Autora:

Laura Cabezas

Universidad de Buenos Aires

Buenos Aires, Argentina

laura.czas@gmail.com

https://orcid.org/0000-0002-1260-2901

Submitted / Recibido: 01/09/2020

Accepted / Aceptado: 16/11/2020

To cite this article / Para citar este artículo: Cabezas, L. (2021). Relecturas e

intervenciones «femeninas»/feministas en la revista La Literatura Argentina. Feminismo/s, 38, 281-306. https://doi.org/10.14198/ fem.2021.38.11

Licence / Licencia:

This work is licensed under a Creative Commons Attribution 4.0 International.

\section{(c) (1)}

(C) Laura Cabezas

\section{Resumen}

La Literatura Argentina conforma un archivo en su materialidad más convencional, nombres propios y obras de escritoras se suceden bajo la lógica del guardado y el almacenamiento; pero, al mismo tiempo, también archiva formas de subjetivación de «lo femenino» en relación con las condiciones de existencia y producción de la literatura en ese momento histórico. Bajo la dinámica de una inclusión excluyente, las escritoras reflexionan e inflexionan sobre el dominio discursivo con un gesto lecto-comprensivo feminista: leen y se leen entre ellas, pero además leen o se leen desde su propia inscripción en ese archivo sexualizado. Esto permite que, más que una interpretación alternativa del archivo, se verifiquen movimientos dentro de él que intentan releer inversamente sus fundamentos patriarcales.

Palabras clave: La Literatura Argentina; escritoras argentinas; relecturas femeninas; archivo y feminismo. 


\begin{abstract}
La Literatura Argentina forms an archive in its most conventional materiality, the proper names and the writers' works follow one another under the logic of saving and storage; but, at the same time, it also archives forms of subjectivation of «the feminine» in relation to the conditions of existence and production of literature at that historical moment. Under the dynamics of an exclusive inclusion, the writers reflect and flex on the discursive domain with a feminist reading-understanding gesture: they are read and read, but also read or read from their own inscription in that sexualized archive. This allows that, more than an alternative interpretation of the archive, movements within it are verified that try to reread its patriarchal foundations in reverse.
\end{abstract}

Keywords: La Literatura Argentina; Argentine women writers; Feminine re-readings; Archive and feminism.

\title{
1. VISIBLEMENTE INVISIBILIZADAS
}

«La obra me ha interesado especialmente por ser de mujer y entiendo la solidaridad femenina naciente, haciendo llegar a las compañeras en lucha y aspiraciones intelectuales, una opinión sincera», se lee en el quinto número -enero de 1929- de la revista La Literatura Argentina. Quien escribe es Mercedes Dantas Lacombe, escritora, profesora y doctora en Filosofía y Letras, cofundadora del Club Argentino de Mujeres, institución que un mes antes había organizado el Tercer Congreso Internacional Femenino y también la Exposición del Libro Femenino. Dantas Lacombe (1929) entonces escribe sobre la obra teatral de Lucía Láinez de Mujica Farías, Y pudo más la razón..., en el marco de un artículo que revisa críticamente los libros de algunas escritoras publicados el año anterior. La necesidad de leer, dar a conocer y hacer balances no extraña. En sus páginas, La Literatura Argentina alienta un proyecto bibliográfico dedicado «exclusivamente al mundo del libro y sus creadores» (Pierini, 2006, p. 93). En efecto, desde septiembre de 1928, la publicación mensual del editor Lorenzo J. Rosso recuerda a los autores del pasado al mismo tiempo que fomenta a los nuevos y nuevas exponentes del campo literario e intelectual $\operatorname{argentino}^{1}$. En este sentido, el objetivo archivístico democratiza la letra, de un

1. Bajo la dirección de Lorenzo J. Rosso (1928- julio de 1936), La Literatura Argentina se publica mensualmente entre septiembre de 1928 y julio-agosto-septiembre de 1937.

Feminismo/s 38, July 2021, 281-306 
modo general y no exento de conflictos, permitiendo el ingreso, de manera creciente, de diversas voces y obras de mujeres que interesan especialmente, como afirmaba Dantas Lacombe (1929).

Tampoco se equivocaba la colaboradora cuando hacía mención a una solidaridad femenina naciente, que en términos literarios se comprueba en la revista-catálogo. En sus sucesivas ediciones, las escritoras van ganando terreno al reflexionar, debatir y disputar un lugar de enunciación válido dentro de una institución literaria que se presenta -y ellas se encargan de remarcarlo- como un asunto de varones letrados. Si bien en otras publicaciones de la época, como Caras y Caretas o El Hogar, las «poetisas» y escritoras encuentran visibilidad al promocionar sus libros, enviar sus textos o conceder entrevistas, en La Literatura Argentina ellas pueden, además, intervenir con sus opiniones personales sobre los mecanismos de legitimación que organizan el canon sexista de las letras. Es que, al plantear un periodismo que se concentre más en la «producción literaria» que en la crítica², la revista habilita y promueve la discusión sobre la dimensión material de la literatura, es decir, sobre los modos del hacer y circular de los libros. Y así, a partir de esta propuesta editorial, las escritoras se piensan a sí mismas como «productoras» y se involucran en las reglas que asocian lo literario a «lo femenino»: ¿qué son la poesía y la literatura femeninas? ¿Cómo se lleva adelante un movimiento cultural de mujeres? ¿Por qué las escritoras no son en general contempladas en los premios, y por qué no hay paridad de género en la conformación del jurado? ¿Quiénes son y sobre qué escriben las autoras del «interior» del país? ¿Cómo conformar una genealogía propia? Estas preguntas, que se suceden en los primeros años en que se publica la revista, dan cuenta de un programa de paridad de género que las escritoras llevan

En total se publicaron 105 números, en Buenos Aires, con dimensiones $28 \times 20 \mathrm{~cm}$. La mayoría de sus números se encuentran digitalizados en AhiRa (Archivo Histórico de Revistas Argentinas), https://www.ahira.com.ar/revistas/la-literatura-argentina/.

2. En el primer número se plantea como uno de los objetivos de la revista el «cómputo» y no la «clasificación», es decir, que no interesa tanto la crítica literaria como fomentar los autores más recientes al mismo tiempo que revisitar a los «de ayer». Asimismo, se propone hacer «noticia del libro escrito y la obra por escribir; del autor conocido, del olvidado, del que se asoma y del inédito aún; de las instituciones y cenáculos literarios, del editor y del librero» (La Literatura Argentina, 1928, s/p).

Feminismo/s 38, July 2021, 281-306 
adelante para que se les reconozca su constante y creciente presencia dentro del ámbito literario nacional.

Fletcher (1993) en «El desierto que no es tal: escritoras y escritura» lanza un interrogante sobre quién conoce o ha leído a las sesenta autoras con noventa libros de narrativa publicados durante la década de 1930 (p. 7). Su propósito es «rescatar una parte de la tradición literaria femenina argentina, una parte tan fecunda como desconocida: la década de 1930» y así demostrar que «la literatura argentina no es una cuestión de escritores varones o algunas escritoras reconocidas» (p. 7). En palabras de la crítica feminista:

Al no tomar en cuenta las otras escritoras - a veces menores, a veces no-se pierde de vista la relación entre ellas como también de la relación entre ellas y sus tiempos, se desconoce la presencia constante de escritoras y sus contribuciones, y se intenta valorizar y periodizar su obra según factores muchas veces ajenas a ellas y su obra. (p. 7)

Los ejemplares de La Literatura Argentina, en este sentido, son un buen espacio para pensar estas cuestiones ya que, como nota Fletcher, el caudal de escritoras y libros supera en número a todas las revistas de la época, literarias y feministas. De hecho, si al principio se publican colaboraciones aisladas aunque recurrentes, desde 1931 se impone una política literaria femenina de secciones: «Libro femenino» a cargo de Raquel Adler (a partir del nro. 37, sept. de 1931), en la que se concentran las notas y críticas bibliográficas sobre los libros de mujeres; «Escritoras del interior» (a partir del nro. 38, octubre de 1931), que recorre los nombres y obras de escritoras de todo el país; «Notitas femeninas» (a partir del nro. 40, dic. de 1931, luego «Notas femeninas»), que divulga actividades e información miscelánea; y «Escritoras sobre escritoras» (a partir del nro. 57, mayo de 1933) en el que una escritora elige a otra y recorre su obra. Si bien considero que el rescate es una parte importante del trabajo de archivo en relación con las escritoras y sus producciones, no es este el objetivo del presente artículo. Me interesa, más bien, rastrear las reafirmaciones colectivas que ellas realizan, sus estrategias de apoderamiento y los debates que generan para cuestionar los criterios legitimantes y habilitantes del canon que las desautoriza.

Como ha señalado Pollock (2013), la crítica del canon es motivada por «aquellos que se sienten sin voz y privados de una historia cultural reconocida» (p. 31), ya que el canon excluye los textos escritos, pintados o 
compuestos e interpretados por su comunidad social, cultural o de género. $\mathrm{Y}$, sin ese reconocimiento, «estos grupos sienten la falta de representaciones de sí mismos para contestar aquellas otras estereotipadas, discriminantes y opresivas que figuran en lo que ha sido canonizado» (p. 31). En el caso de La Literatura Argentina, la respuesta se debate entre quienes defienden y quienes desestiman la apuesta por un sexo literario «femenino» que organice un canon de escritoras y compita con el oficial, masculino y masculinizante. Sea una u otra la posición tomada, lo cierto es que ambas tratan de dar una discusión mayor en relación con los derechos intelectuales de las mujeres, en tanto ven que, pese a la gran visibilidad que tienen en la prensa, carecen de una representación autorizada de sí mismas como autoras.

Un buen ejemplo aparece en el número 62, octubre de 1933. Ese año se discute la Ley de Propiedad Literaria y Artística, y se realiza una entrevista a la abogada Lucila de Gregorio Lavié, quien había dado una conferencia en el Ateneo Ibero Americano sobre la protección jurídica de las obras artísticas y literarias. Gregorio Lavié explica cómo la nueva Ley de Propiedad viene a llenar un vacío, una necesidad apremiante, y se muestra entusiasmada por la numerosa concurrencia femenina que asistió a la conferencia y produjo comentarios muy interesantes. La ironía del entrevistador no tarda en llegar: «Teníamos conocimiento de la documentada conferencia que diera en el Ateneo y en la que fuera largamente aplaudida; pero, no resistimos el deseo de hacerle una pregunta capciosa: ¿Qué puede interesar este tema a tantas lindas damas?» (Entrevista a Lucila De Gregorio Lavié, 1933, p. 32). Gregorio Lavié replica que la mujer se intelectualiza día a día, aumenta su cultura y se lanza con entusiasmo a nuevas conquistas; remarca cómo en las letras, la música, las artes y el periodismo se destacan cada vez más «valores femeninos» y sentencia: «no es desde luego de extrañar que se interesen por algo que les atañe bien de cerca» (p. 31). El argumento de cercanía acompaña un dato de época: la mención, con diferentes connotaciones, al número cada vez más creciente de escritoras en el campo literario ${ }^{3}$. Ahora bien, la capciosidad de

3. Como señalan Szurmuk y Torre (2018), «[1]as mujeres burguesas habían estado reclamando un espacio en el mundo letrado desde principios del siglo XIX y, a fines de la década de 1880 , muchas de ellas ya publicaban libros y diarios. Las mujeres inmigrantes, las de la clase trabajadora y las de clase media baja se alfabetizaron y comenzaron a escribir como parte de su compromiso con la política, con los sindicatos y con la

Feminismo/s 38, July 2021, 281-306 
la pregunta viene justamente a mostrar los límites impuestos al consenso de lo visible. La profusión de «poetisas», poetas y escritoras en revistas y diarios oculta un mecanismo cultural de poder implícito: se las incluye desde la exclusión que sostiene la narrativa de la diferencia sexual. Están visiblemente invisibilizadas, y sus textos, al igual que sus cuerpos, se tornan objetos femeninos de exhibición.

La Literatura Argentina, ya se dijo, conforma un archivo en su materialidad más convencional, nombres propios y obras se suceden bajo la lógica del guardado y el almacenamiento; pero, al mismo tiempo, también archiva formas de subjetivación de «lo femenino» en relación con las condiciones de existencia y producción de la literatura en ese momento histórico ${ }^{4}$. Bajo la dinámica de una inclusión excluyente, las escritoras reflexionan e inflexionan sobre el dominio discursivo con un gesto lecto-comprensivo feminista: leen y se leen entre ellas, pero además leen o se leen desde su propia inscripción en ese archivo sexualizado. Esto permite que, más que una interpretación alternativa del archivo, se verifiquen movimientos dentro de él que intentan releer inversamente sus fundamentos patriarcales. En este sentido, la emoción como atributo social, cultural y editorial de «lo femenino» se propone en muchos momentos como una marca identitaria y una cifra de empoderamiento.

Las emociones o sentimientos no son solamente materia lírica y narrativa en las escritoras, no son tampoco «propiedad» de su género, configuran la posibilidad misma de problematizar la condición subalterna de sus voces autorales mediante la interpretación: no porque las escritoras se pongan a interpretar lo que sienten, sino porque reaccionan desde un lugar de enunciación que articula cuerpos, emociones e historia. Que las emociones no solo mueven y hacen sentir, sino que también, como sostiene Ahmed (2015), conectan cuerpos con otros cuerpos es muy claro en la revista a través de la conformación de una comunidad de escritoras que iremos recorriendo, entre las que se encuentran María Raquel Adler, María Velasco y Arias, Nydia Lamarque, Rosa Bazán de Cámara, María Alicia Domínguez, Margarita del

educación. Fueron piezas clave en la expansión del público lector a través de la enseñanza, la publicación y la escritura» (p. 191). Por este motivo, en el periodo de 1880 a 1930, las escritoras no pueden considerarse «excéntricas, pioneras o rebeldes» (p. 191). 4. Sobre la noción de archivo, Agamben (2002), Foucault (1992, 1997) Gi y Guasch (2011).

Feminismo/s 38, July 2021, 281-306 
Campo, Herminia C. Brumana, Mary Rega Molina, quienes depositan sus sueños, expectativas, enunciados en pos de construirse una realidad escrituraria como tarea del presente y promesa de futuro.

\section{APODERADAS DE LA POESÍA}

«Cherie García y Onrubia canta con sencillez las emociones que siente. Su verso es fluido y musical; su estrofa contenida y sobria. No pertenece, en verdad, a ninguna escuela determinada ni se empeña por sorprender al lector con melodías extravagantes o expresiones inesperadas. Quiere solamente cantar sus sentimientos con voz natural» (Chérie García y Onrubia. Vidriales, 1928, p. 23)5. Sin firma, el fragmento pertenece a las reseñas que, producidas en serie, al límite de la escritura no creativa, se detienen en las obras literarias de las escritoras. Sinceridad, corazón, sencillez, simplicidad natural, expresión conmovedora, delicados versos, sentimientos tiernos y espontáneos, intimidad, frescura..., la lista sigue, y este sistema de adjetivación, relativamente estable, cimienta el imaginario de una literatura «naturalmente» femenina que, si bien se encarniza en las «poetisas» y sus versos, no por eso deja afuera a las escritoras reconocidas, como Victoria Ocampo, o las obras en prosa. En la mitología patriarcal de creatividad exclusivamente masculina (Pollock, 2013, p. 33), a las escritoras les toca sentir y reproducir, de forma subjetiva y por tanto individual, su emocionalidad que, como en el caso de Chérie García, no pertenece a una escuela estética determinada ni sorprende al lector con la alteridad de lo extraño.

Como se sabe, el discurso sobre la «naturaleza femenina» que se formuló a partir del siglo XVIII y se impuso en la sociedad burguesa en ascenso, definió a la mujer en términos maternales y delicados, una «fuerza del bien» que se trastocaba en «potencia del mal» cuando «usurpaba» actividades que no le eran «culturalmente» atribuidas (Telles, 2010), de tal modo que este discurso que naturalizó «lo femenino», también lo colocó en un más allá de la cultura: si la creación era una prerrogativa de los hombres, a las mujeres les correspondía la reproducción de la especie y su nutrición. Por estar «más

5. Seudónimo de Sarah Felisa García y Onrubia (1909-1925), editó su primer libro en 1928, Vidriales, y colaboró en algunas revistas, como El Hogar, Fray Mocho, en diarios como El Diario Español, La Capital de Rosario y O Jornal de Río de Janeiro.

Feminismo/s 38, July 2021, 281-306 
cercanas» a la naturaleza, las mujeres también quedaban vinculadas con las emociones que se consideraban «inferiores» a las facultades del pensamiento y la razón. En palabras de Ahmed (2015), «se narran como un signo de 'nuestra' prehistoria y de la manera en que persiste lo primitivo en el presente» (p. 22): están «por debajo» y «por detrás» del hombre/humano. De este modo, sigue Ahmed (2015), afirmar que un sujeto o colectivo es emotivo implica una clara dependencia de las relaciones de poder, que dotan a «otros» de significado y valor. Dentro de este esquema evolutivo, «lo femenino» en cruce con la literatura conlleva un mecanismo perverso de control y valoración: si, por un lado, se celebra la encantadora feminidad en las letras como marca de género del sujeto y de su textualidad, por el otro, la falta de esta cualidad femenina se utiliza como elogio. En una reseña al libro En silencio, a Margarita E. Arsamasseva ${ }^{6}$ se la presenta como «un espíritu investigador», que manifiesta su pensamiento y, por tanto, «tiene muy poco de femenina». (Margarita E. Armasseva, En silencio, 1929, p. 24).

Si bien «lo femenino» siempre atañe a los sujetos construidos social y culturalmente como «mujeres», no alcanza a todas. Quienes no performan literariamente el género asignado, es decir, las escritoras que no plasman en sus textos sus emociones presuntamente naturales, se ubican más cerca del pensamiento masculino y, por lo tanto, estarían más «avanzadas» en la línea de evolución de la creación estética. Como explica Velasco y Arias $^{7}$ (1931), en una entrevista, el hombre «califica, y si a regañadientes tiene que reconocer una valía inobjetable la arrima al grupo de la producción masculina mudando el género gramatical de las palabras aplicables a la artista» (p. 8). Son las «escritoras viriles» como contracara de las escritoras del corazón, del misticismo y el idealismo: las llamadas «poetisas». Aunque, como ya dijimos, estas caracterizaciones nunca son estables, y lo masculino incluso puede convivir con lo femenino, como ocurre en la reseña del libro Mosaico

6. Son pocos los datos biográficos que se conocen de esta poeta, sabemos que participó en la Revista Multicolor de los Sábados del diario Crítica.

7. María Velasco y Arias es la primera mujer que recibe el título de doctora en la Facultad de Filosofía y Letras (UBA), en 1913, con una tesis sobre la historia teatral argentina. Además, escribió la biografía de Juana Manso (1937). Publicó Alborada del canto, en 1947 y Cerca pasa el río, de 1948.

Feminismo/s 38, July 2021, 281-306 
de Herminia C. Brumana ${ }^{8}$ que «tiene cerebro y también corazón»: «Cerebro para el libre examen, corazón abierto a todas las emociones humanas, nervios para el arrojo. [...] Porque en todo, aun en su feminidad, es un libro masculino, escrito por una mujer» (Mosaico de Herminia C. Brumana, 1929, p. 117).

Ahora bien, frente a esta dicotomía entre razón y sentimiento, en La Literatura Argentina las escritoras forjan un discurso que no reniega de su «emocionalidad femenina», al contrario: la reafirma. Y lo hace desarmando la oposición entre emoción y pensamiento racional. Algunas de las escritoras que escriben y opinan en la revista intentan usar la emoción que se les adjudica como forma de emancipación intelectual. Así lo exhiben las jóvenes premiadas en el concurso literario femenino organizado por el Club Argentino de mujeres en 1929. Por ejemplo, Tilde Pérez Pieroni ${ }^{9}$, segundo premio de poesía, afirma que le inspira la naturaleza y el misterio de su intimidad, sostiene el progreso intelectual de la mujer y opina que la prevención del «hombre de 20 a 40 años» contra la mujer escritora se debe a que «ansía siempre ser superior a ella y se resiste a admitir que un cerebro femenino pueda aventajarle en ingenio; tal vez impere en su ley manifestar eterna superioridad tanto intelectual como espiritual, quizá bajo la influencia del privilegio que la sociedad le concede» (El concurso literario del Club Argentino de Mujeres, 1929, p. 10). Cómo un «cerebro femenino» puede combatir ese privilegio del género masculino en las letras argentinas es una reflexión constante en las intervenciones de las escritoras. Les urge, por eso, crear un lugar de enunciación propia, una filiación y una comunidad que sea intelectual y femenina al mismo tiempo.

8. Herminia C. Brumana (1897-1954). Maestra, educadora, escritora, periodista, dramaturga y militante de ideas socialistas y anarquistas. Defendía los derechos de las mujeres, el amor libre, el derecho al divorcio y le interesaba particularmente la niñez. Tiene una gran producción en prosa y dramaturgia. Colaboró en varias publicaciones periódicas de la época, como El Hogar, La Nación, Mundo Argentino.

9. Tilde Pérez Pieroni (1913-) nace en Bolívar, provincia de Buenos Aires, donde comienza a publicar composiciones en verso y en prosa (por ejemplo, en la Revista Cultural de Bolívar y en los periódicos La Verdad y Rivadavia). Luego en La Plata, publica en Eurindia, Nuestro Mundo y El Estudiantes. En el primer concurso literario femenino realizado por el Club Argentino de Mujeres, en agosto de 1929, obtuvo el segundo premio de poesía por su trabajo Amazona.

Feminismo/s 38, July 2021, 281-306 
$\mathrm{Y}$ en este armado de un archivo femenino, que se percibe a veces como feminista, Raquel Adler ${ }^{10}$ ocupa un lugar central. La mujer «está llamada a ser el único poeta del futuro», sostiene en la primera entrevista que le conceden en la revista (Raquel Adler presenta un panorama..., 1929, p. 36). $\mathrm{Y}$, sorprendentemente, el argumento que esgrime es «su falta de herencia cultural y aun de producción», ya que, sostiene, "precisamente porque no ha explotado en forma continua la poesía, como lo hizo el hombre, salvo contadas excepciones, tiene para ello una originalidad y una fuerza de expresión fresca, pura, intensa, honda... así como debe ser la poesía» (p. 36). La inversión de valoración histórica es clave en la lectura que hace Adler de la situación de las mujeres: el ingreso demorado a la cultura letrada las hace «naturalmente» más aptas para el tono poético que, en su visión, se guía por una «emoción creadora». Resulta interesante que esta operación crítica sigue de cierta manera el modo de funcionamiento que ella lee en la vanguardia. Unos meses más tarde, se publica parte de una entrevista censurada que le habían realizado en un diario de Rosario, en la que expresaba sus apreciaciones sobre la «nueva sensibilidad». Pese a no cultivar en su propia escritura las premisas de este proyecto literario y artístico, la poeta mística ve positivamente «la revolución en la forma, en la emoción, en la idea», en tanto «los adeptos de tal movimiento bregan por una libertad desconocida por los demás, intuida por ellos» (Adler, 1930b, p. 167). Para Raquel Adler, los vanguardistas son el «caudillaje de una renovación moral y social del arte» y poseen como baluarte «la libertad máxima» y como ideal «la perfección a través su imperfección» (p. 167). Libres e imperfectos, vanguardistas y mujeres se encontrarían en esa lucha que transitan los «neosensibles» contra la «tiranía y opresión que ejercen los fuertes sobre los débiles, es decir, la forma adaptada y fiscalizada sobre la palabra balbuciente y trémula de nuevos horizontes y quizá de nuevos ideales» (p. 167).

El gesto de expropiación-apropiación del género poesía por parte de las mujeres se repite y se matiza en otras declaraciones de Raquel Adler. En la

10. María Raquel Adler (1901-1974). Poetisa, mística y católica conversa. Publicó Revelación en 1922, Místicas en 1923, La divina tortura en 1927, De Israel a Cristo, en 1933, y el libro de ensayos De la tierra al cielo, en 1936, entre otros. Integró la comisión directiva de la Sociedad Argentina de Escritores, fue parte de la Asociación de Escritoras y Publicistas Católicas (ASESCA) en 1939.

Feminismo/s 38, July 2021, 281-306 
reseña de la Antología de la poesía femenina argentina (1930a, p. 41), después de comentar el cuadro desparejo pero necesario de las numerosas «poetisas», como «representantes de la múltiple Buenos Aires, o como acento de lejanas provincias», vuelve sobre el tema: «Y para terminar, voy a formular una pregunta a mis colegas los poetas-hombres: ¿no les parece que la mujer se ha apoderado en demasía de la poesía, y que en algunos casos tiende ya a desplazarles por completo?» (p. 41). Adler alienta a que las escritoras se conviertan en las apoderadas de la poesía como una primera instancia de legitimidad en el campo literario.

Un año después ejerce un desplazamiento en sus palabras, en el discurso inicial de la Exposición femenina del Libro Latinoamericano, la mujer ya no viene a suplantar al hombre, sino a colaborar con él (Exposición femenina del Libro Latino = americano, 1931, p. 365). Finalmente, en 1933, retoma el tema en un artículo que responde a Arturo Cancela, quien en El Hogar había manifestado la afluencia de las mujeres en el campo literario como un serio peligro y competencia para los escritores. En su respuesta, Adler (1933) revisa el lugar de la mujer en los últimos doce años y pregunta quién hubiera creído que ella se habría de proyectar en la profesión de escritora; a su vez, también revisa su propio razonamiento:

Yo dije en 1929 en la revista bibliográfica La Literatura argentina, sin ninguna premeditación especial, de que las poetisas vendrían en un mañana cercano a reemplazar a las poetas. Y reemplazar no es suplantar. Se reemplaza un lugar que ha quedado vacío o vacante, por deserción o por alejamiento del que lo ha ocupado. Y la hora actual del mundo no es como para que el hombre se detenga a escribir versos. La vida pide vigor, y voluntad, y no sentimentalismo; conciencia y criterio, y no ausencia despreocupada del instante caótico por el que pasamos. (p. 284)

En este fragmento se perfecciona la «treta»-un tanto débil- de la poeta-crítica enunciada cuatro años antes. Al valerse de la oposición entre lo público masculino y lo privado femenino, Adler (1933) supone un espacio vacante, dejado por los hombres ocupados en los asuntos sociales y políticos, que las mujeres pueden ocupar: «las letras son quehaceres delicados, creados, se puede decir, para ser desempeñadas por las manos sutiles de la mujer» (p. 284). Ya no es la poesía, es toda la literatura de la que puede apropiarse. La pesadilla temida por Cancela se hace realidad en la propuesta de Adler. Porque no se rompe

Feminismo/s 38, July 2021, 281-306 
con el estereotipo, sino que se exagera y reafirma la sexualización del género en un sentido doble: «lo femenino» identifica subjetividades y escrituras. De modo tal que la llamada literatura femenina existe en y a través de un conjunto de actos de lectura y escritura que repiten y remiten, sin conflicto, al sujeto autoral. Así, lejos de buscar «travestir» sus voces (Méndez, 2017), Adler alienta a performar la feminidad hegemónica literaria desde una de las paradojas más transitadas por las escritoras en el período: arremeten contra su invisibilidad y su no valoración, pero se legitiman mediante las normas de género vigentes que materializan ese reparto desigual de lo visible.

Sin embargo, no por esto es menor la apuesta de Raquel Adler en La Literatura Argentina. La segregación en torno a la «literatura femenina» impone una reafirmación colectiva que se traduce en la conformación de un movimiento femenino o «de la mujer que escribe», necesario para hacerse oír en un campo editorial que las dejaba hablar pero no las escuchaba. En la sección inaugural de «Escritoras del interior», Adler (1931b) escribe:

Hay en nuestro medio intelectual un grupo numeroso de mujeres que escriben. Tierra adentro y en la capital han decidido a ocupar sus ocios, sus inclinaciones, o su vocación a las letras. Justo es pues que se las escuche; justo es también que se las comprenda. Fuera de un grupo escasísimo de escritoras (poetisas o prosistas) que tuvimos la facilidad, el premio o la destreza de publicar en diarios y revistas, y de hacernos conocer por un público, si bien escaso, atento, que lee y sigue de cerca el desenvolvimiento de algunas mujeres de talento, quedan sumidas en el olvido o en la indiferencia total el $90 \%$ de las escritoras del país. (p. 39)

Hay un gesto sindical y federalizante en la propuesta de Adler $^{11}$ que puede vincularse con su catolicismo, su vida en Bernal y su pertenencia a la clase trabajadora. Hacer valer la voz de las escritoras entonces supone la movilización. Y este acto involucra una memoria y un tener lugar dentro del archivo de reivindicaciones de mujeres: por un lado, la inscripción del acompañamiento y representación propia de las escritoras, a escala nacional, como parte de las

11. En un uno de sus ensayos compilados en De la tierra al cielo, de 1936, Adler proclama la necesidad de un "gremio de poetisas» que se organicen y reclamen un lugar de respeto en el ámbito literario argentino.

Feminismo/s 38, July 2021, 281-306 
luchas de mujeres en el ámbito social en la década del veinte ${ }^{12}$; por el otro, el armado de un linaje trasnacional de escritoras que precede y fundamenta una literatura femenina. De este modo, si el valor literario, impuesto desde la autoridad del patriarcado cultural, no se pone en cuestión, sí se esboza una suerte de justicia literaria. ¿Qué es lo justo para las escritoras? Esta es una pregunta que se plantea recurrentemente en La Literatura Argentina, desde diversas modalidades, pero bajo una emoción compartida: la indignación como ejercicio de lectura y (auto)comprensión.

\section{PREMIOS E INDIGNACIÓN}

«Hablan para La Literatura Argentina todos los premiados y la única mujer votada en el concurso literario municipal, definiendo sus personalidades, sus juicios sobre el fallo y sus propósitos» (1929, p. 13). El titular inaugura una de las batallas más fuertes que las escritoras dan en la revista, su exclusión de las instancias de consagración que conllevaría no reconocerlas como autoras y seguir considerándolas «aficionadas» de la literatura. En este sentido, la «defensa de la mujer» que realiza Enrique González Tuñón en ese artículo se sostiene sobre la ambivalencia. Si bien afirma que «se ha sido ingrato con la mujer», y menciona a «autoras de valer» como María Luisa Carnelli o Pilar de Lusarreta ${ }^{13}$, termina afirmando: «Siquiera para fomentar la afición en la mujer, debió haberse contemplado ese aspecto» (Hablan para La Literatura Argentina..., 1929, p. 16). A González Tuñón le genera incomodidad el fallo ya que, según sus palabras, «daría la sensación de que los premios municipales han sido creados nada más que para el hombre» (p. 16). Pero, cabe

12. La actuación de los feminismos en los años 20 fue muy relevante ya que consiguieron mayor organización, constancia y amplitud para obtener las garantías que aparecían en otras latitudes, como explica Barrancos (2007) y menciona a Julieta Lanteri, a la creación del Partido Feminista Nacional y a las publicaciones Nosotras y La Nueva Mujer de María Abella Ramírez.

13. María Luisa Carnello (1898-1987) se desempeñó como periodista y formó parte de los «escritores del margen». Escribió tangos, poesía y una novela, ¡Quiero trabajo! En 1933. Entre 1933 y 1937 vivió en España y escribió a favor de la República. Pilar de Lusarreta (1903-1967) incursionó en varios géneros de escritura, poesía, crítica literaria, crítica de arte. También fue locutora y periodista. Entre su extensa producción, podemos mencionar Cinco dandis porteños, Hombres en mi vida y sus Crónicas bibliográficas. 
preguntarse, ¿cómo se premia un pasatiempo o una práctica aficionada? Por su parte, Mary Rega Molina ${ }^{14}$, la única ganadora con un libro que compila sus poesías recitadas, también se queja de la poca atención que merecieron las mujeres y plantea un desafío en línea con Raquel Adler, pero sin su ironía: «¿Será que el hombre siempre piensa que se le quiere usurpar el puesto?» (Hablan para La Literatura Argentina..., 1929, p. 17), pero pondera con orgullo «mantenerse estrictamente dentro de los límites de la feminidad» (p. 17). En el número siguiente no aparecerá en la foto de los premiados (ver imágenes 1 y 2).

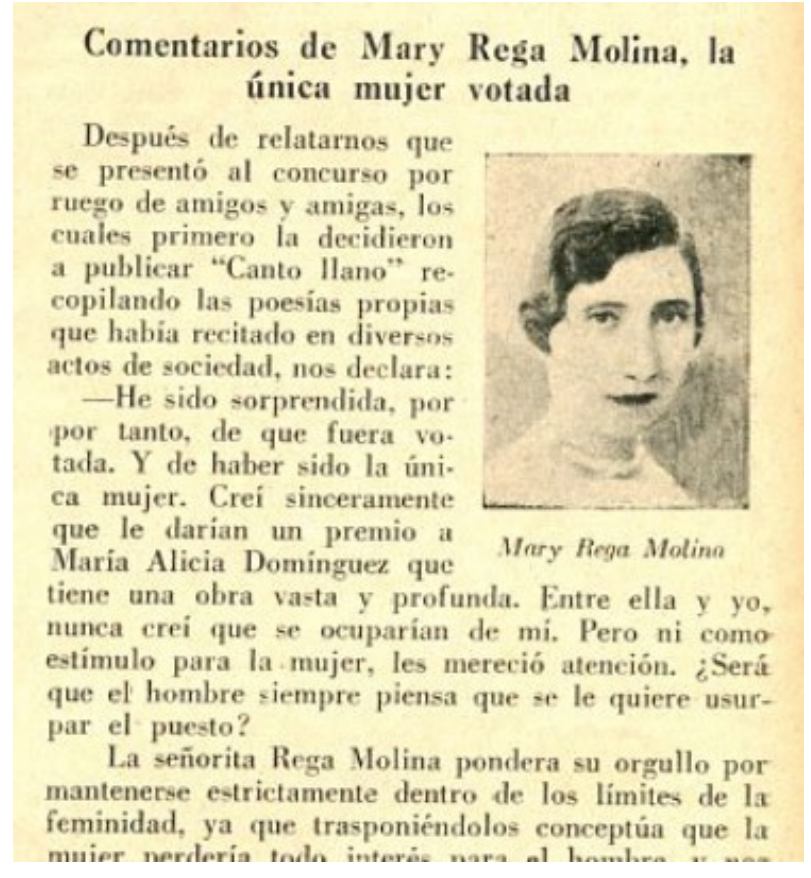

Imagen 1. Fragmento del artículo «Hablan para La Literatura Argentina todos los premiados y la única mujer votada en el concurso literario municipal, definiendo sus personalidades, sus juicios sobre el fallo y sus propósitos», La Literatura Argentina, n. 10, junio, 1929, pp. 13-17.

14. Mary Rega Molina de Méndez Caldeira (1895-1960) fue poeta, escritora y docente. Integró varias asociaciones católicas, incluyendo la Asociación de Escritoras y Publicistas Católicas, como Raquel Adler. Colaboró en diarios y revistas. 
12

\section{LA LITERATURA ARGENTINA}

Camuatí ofreció una simpática fiesta a los autores premiados en el concurso literario municipal

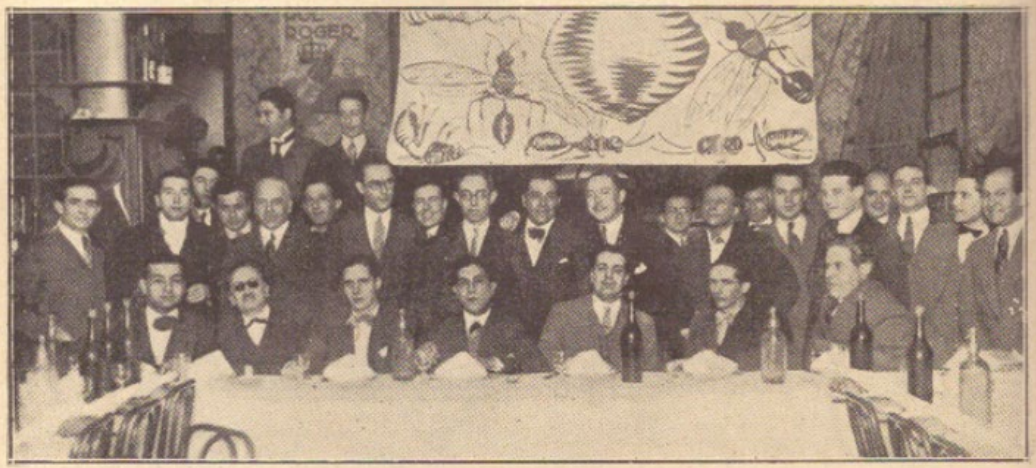

Sentados, de ixquierda a derecha: Gaspar Besares Soruire, Enrique Richard Laralle, Raúl Gontátrz Tuñón. Rafael Jijena Sinchez, Jorge Luis Borges, Enrique González TuKbn. Gleizer. Parados, y no siguiendo un riguroso ordea de colocaclón: Antonio Garguinlo. Guillermo Richard Latalle, Alberto Diana Laxalle, Salarerry. José Antonio Saldias. Pedro Lamadrid, Nestor Ibarra, Jacobo Fijman. Pampezo Andier, Kornblit, Alberto Ruiz, Rufino, Pablo Tosto, Enrique Suárez, Rodeljo Irazasta, Vicente Fosselli, A. Rinos Grande.

Imagen 2. La Literatura Argentina, n. 11, julio de 1929.

Si bien hay instancias de exhibición de las producciones de mujeres, como los premios otorgados por el Club Argentino de Mujeres y la Biblioteca del Consejo Nacional de Mujeres, o las exposiciones del libro femenino latinoamericano organizadas por el Ateneo Femenino de Buenos Aires o el «Club del Progreso», las escritoras disputan su lugar dentro de los Premios Municipales dejando a un lado la segregación de género. Pero lo desafiante de esta batalla literaria es que no solo las motiva la premiación, sino también la posibilidad de ejercer la elección. Raquel Adler, nuevamente, será una de las voces más activas en esta reivindicación. Así, por ejemplo, en marzo de 1931 responde preguntas sobre los autores que votaría si fuera jurado y tres meses después se publica un artículo titulado «Las escritoras versus el Jurado Municipal», en el que Adler transcribe la carta de una supuesta lectora chaqueña de La Literatura Argentina y admiradora suya. Teresa González, una retirada Inspectora de Escuelas, defiende a la poetisa bonaerense contra un malentendido que tuvo con Nydia Lamarque y expresa su desilusión al saber que el Jurado Municipal no había premiado a ninguna mujer. Menciona a Margarita Abella Caprile, a

Feminismo/s 38, July 2021, 281-306 
María Alicia Domínguez, a Nydia Lamarque y a Norah Lange para preguntarse por qué no se premió a ninguna de ellas y responderse:

Será porque no son hombres. ¡Cómo me exaspera todo esto! ¡Siempre han de ser ellos! Deberían batir de una vez la retirada. Este es el siglo de la mujer. Desde los tiempos clásicos de Atenas y Roma, desde antes aun, el hombre no hizo más que imponerse y ganar. La mujer es como un segundo Él; y tanto hicieron los años y la costumbre que el hombre se creyó un ser exclusivo, único, para desempeñar las funciones del mundo. Pero felizmente los tiempos cambiaron. (Adler, 1931c, pp. 315-316) ) $^{15}$

La carta expresa tal virulencia que se entiende la elección por una máscara de identidad escrituraria. Como una Sor Juana argentina del siglo XX, Adler (1931b) se esconde para poder dar rienda suelta a sus emociones como una forma de politizar la discusión. De hecho, ya se anunciaba el carácter emocional y performático que tendría el texto al presentarse a la lectora como una mujer gesticulada que «se yergue, protesta, avanza, retrocede, y hasta abraza y besa a través de su carta» (p. 315). Los signos de exclamación y la exasperación que transmiten dan cuenta de la frustración que genera la «lucha sin tregua» (p. 315) entre sexos que se lleva a cabo en el campo literario. Pero los tiempos de ser un «segundo Él» terminaron para las mujeres, por eso tal vez Adler idea una aliada que posibilite un «nosotras».

Razona con ironía la polemista que «El Concurso Municipal compuesto continuamente de un jurado de hombres premia naturalmente la mayoría de hombres» (Adler, 1931b, p. 316) y recuerda que el 50\% de la producción del país corresponde a mujeres, por lo tanto: «El Jurado Municipal debería componerse en lo sucesivo de igual número de mujeres y hombres» (p. 316). Números, paridad de género y apropiación literaria, los clásicos argumentos adlerianos, se ponen en escena en la carta, pero se llevan un poco más lejos, como se lee en la competencia sexo-literaria que organiza entre poetas y poetisas:

A los Banchs, los Blomberg, los Fernández Moreno, Arrieta, Rega Molina, etc., se le puede ofrecer una revancha notable: de una Storni, una Adler, (discúlpeseme la vanidad de la transcripción) una Abella Caprile, una Lamarque, Domínguez, Calandrelli, Bertolé, Rega Molina, García Costa,

15. Las cursivas me pertenecen.

Feminismo/s 38, July 2021, 281-306 
etc. Hasta creo que Vds. saldrían ganando. La poesía de nuestros poetas es más bien pasiva. En cambio la de las poetisas es activa hasta en la vena erótica (Srta. Storni). (Adler, 1931b, p. 316)

No importa tanto si gana el equipo masculino, al que se interpela de forma directa, lo central es que el partido sigue y Raquel Adler confía en que ellas podrán revertir el resultado final. Hay algo mesiánico en la forma de entender la figura de la mujer que, como ya habíamos visto y acá se repite, sería la única capaz de contrarrestar la descomposición de valores actual. La realidad es que Adler no se esmera mucho en disimular su estilo y sus opiniones ya compartidas en la revista. Y esto se debe, creo, a que la función del alter ego no es hacer nuevas declaraciones, sino más bien intensificar el tono, hasta ponerlo en relación con el feminismo:

Vd. seguramente me tildará de feminista. Si la doctora Lanteri o la Moreau conocieran mi pensamiento, de seguro me invitarían a pasar a sus filas. Hoy lo creo necesario en mi patria. Como un buen soldado, bregaré siempre por la mujer, en el ejército armonioso y disciplinado de su encanto y de su espíritu. (Adler, 1931b, p. 316)

A diferencia de Raquel Adler, que nunca llega a declararse feminista, aunque contribuya a visibilizar la desigualdad sexual que impregna el canon y ámbito literario argentinos, Teresa González no tiene miedo a que la «tilden» de feminista, porque sabe que es imposible sortear el calificativo cuando la indignación toma el cuerpo y se traslada a la escritura. Indignación y feminismo se presuponen, pues, como explica Ahmed, la indignación ya involucra una lectura específica del mundo e «identificarse como feminista implica que se toma esa indignación como la base para una crítica del mundo, como tal» (2015, p. 259). En la propia Adler la indignación no está borrada pero sí intelectualizada, algo curioso para una poetisa que reclama el canto de los sentimientos.

Al final del artículo-carta, su voz regresa bajo la forma del «Manifiesto», que dirige al señor Intendente de Buenos Aires, José Guerrido, exigiendo: en primer lugar, que «haga extensivo el artículo que trata de la formación del Jurado del Concurso Municipal de Letras, para que entren en su formación igual número de mujeres y de hombres»; en segundo lugar, que los premios se acuerden equitativamente; y en tercer lugar, aclara que las escritoras que redactaron el manifiesto (no las menciona) consideran a la literatura una 
profesión y al arte, un factor estético y de cultura. Tres meses más tarde, en septiembre de 1931, se atisban algunos resultados. Por un lado, Adler escribe nuevamente sobre los premios y los jurados para manifestarse sobre una solución positiva aunque «no resolvedora del todo» (1931a, p. 10): la designación, vía Intendencia, de una mujer escritora, Alfonsina Storni, como miembro del Jurado. Adler, que enuncia en nombre de La Literatura Argentina, no confía en la efectividad de una ecuación que da una contra seis: «Mucho nos tememos que el miembro femenino del Jurado Municipal sea solo una figura decorativa de efectismo y de novedad» (p. 10). No se equivocaba. En esa premiación escandalosa de $1931^{16}$, Margarita Abella Caprile ${ }^{17}$ podría haber ganado el primer premio, pero queda descalificada por estar su libro «impreso» en París aunque «editado» en Buenos Aires, como ella misma lo aclara en una carta enviada a la revista ${ }^{18}$. Sin embargo, la batalla de las premiaciones y la lucha por la paridad de género sí le dieron a Adler la consagración, que se anticipa en el enunciado colectivo que usaba en su artículo de septiembre de 1931. Desde ese número, se convierte en la responsable de la sección femenina de la revista y se posiciona como la «encargada del movimiento femenino de La Literatura Argentina» (Notas femeninas, 1931, p. 26).

Ahora bien, si una comunidad de mujeres que escribe heterogénea y plural, se visibiliza en la revista, hasta llegar a tener sus secciones propias, la pregunta que sobrevuela es ¿cómo definir la categoría escritora en términos profesionales?

16. Se supo que el primer premio, dado a un escritor desconocido, había estado arreglado. Alfonsina Storni y Armando Cascella renunciaron provocando un gran escándalo mediático.

17. Margarita Abella Caprile (1901-1960) fue una escritora, poetisa, prosista y periodista. Nieta de Bartolomé Mitre, escribió Ensayos en 1917, Nieve en 1919, Sonetos en 1931, entre otros libros.

18. En «Una aclaración de Margarita Abella Caprile», la escritora aclara su exclusión del concurso: «La Ordenanza dice: 'los libros deberán ser editados en Buenos Aires'. No dice impresos. [...] Hubiera aceptado con humildad, distraídamente tal vez, mi exclusión del premio por no merecerlo ¡son tan relativas las opiniones! Lo triste es haber visto mezclado en pequeñeces a algún Jurado que uno imaginaba ya muy por encima de estas cosas». (1932, p. 183)

Feminismo/s 38, July 2021, 281-306 


\section{ESCRITORA NO SE NACE, SE HACE, Y SE SIENTE}

En el panorama literario de 1928, Buceta $(1929)^{19}$ exhibe la dificultad de leer debido a su situación económica. No cree en los escritores o poetas que «viven de luna y horizontes rosados» (p. 11), porque «si quieren vivir han de comer» y ganarse su pan «no con la pluma» (p. 11). Maestra particular, echa una dosis de realidad sobre la labor de una trabajadora que escribe y, desde esa interseccionalidad entre género y clase, arremete contra el mito del genio burgués, propiedad natural de los hombres creadores. En sintonía con ciertas reflexiones ya esbozadas por Storni (2002) sobre la difícil relación entre el «genio» y la literatura «femenina $»^{20}$, Buceta arremete contra la idea culturalmente aceptada que presenta al genio como una individualidad creativa que conlleva la superación de obstáculos sociales y construye el arte y la literatura como una esfera inexplicable, casi mágica, que debe ser venerada (Pollock, 2013, p. 57). Pero no solo se desacraliza al genio, también se desacraliza el libro. «No leo más que lo que hallo en algún diario o revista que cae alguna vez en mis manos. Los libros no se han escrito para mí como no se hacen juguetes para los niños pobres» (Buceta, 1929, p. 11), sentencia y agrega que la producción literaria no puede juzgarse solamente por los libros editados:

Yo he escrito y publicado versos para formar un buen tomo de poesías que hasta título tiene: «Pequeños Mundos». Sin embargo, como nadie ha visto un libro de versos míos, no soy poetisa.

He venido publicando los cuentos de «El diente de oro» y otros muchos más desde 1926 hasta la fecha sin que por eso existiera. No obstante, desde que tuve la suerte de que me los editaran formando un volumen, dicen que soy escritora y recibo alentadoras cartas de personalidades que no nombro. (p. 11)

Reconocida por su humor e ironía, Clotilde Buceta enfatiza el papel central que tienen los diarios y revistas en la constitución de las escritoras y lectoras,

19. Poco se sabe de esta escritora. Poetisa, colaboradora de Caras y caretas. El diente de oro de 1928 es su libro más conocido.

20. En «La mujer como novelista», Storni afirmaba «Se ha dicho que una vida extraordinaria es, casi siempre, complemento del genio. ¿Como podría la mujer, delicada por naturaleza, limitada por el ambiente y por su propia sensibilidad, vivir esta vida extraordinaria que la haría comprender, ahondar, zambullirse, por decirlo así, en los más interesantes y hondos tumultos del alma humana?» (2002, p. 983).

Feminismo/s 38, July 2021, 281-306 
desde un marco que se presenta democratizador. Y no se equivoca, desde el siglo XIX la prensa fue un instrumento fundamental para el acceso de las mujeres a la escritura, y es en el marco de los periódicos para mujeres, explica Vicens (2017), donde asoman los primeros debates alrededor de la autoría femenina y sus vínculos con el mundo del trabajo. En este sentido, como apunta Masiello, «la figura del escritor profesional, a menudo considerado como un fenómeno que acompañó al modernismo, puede encontrarse en la escritura de las mujeres desde los años posteriores al régimen de Rosas» (1997, p. 49). El salto que propone Masiello indica también una relación diferente con el Estado. Si en la Argentina la escritura profesional de los varones letrados está íntimamente vinculada con el nacionalismo cultural como ideología de Estado $^{21}$, las mujeres que, al escribir, sabotean la familia como misión patriótica y microcosmos estatal, terminan colocando a la emoción como trazo distinguido y diferenciado de su subjetividad laboral.

«¿Qué se entiende por escritora, mágica palabrita tan manoseada que, a fuerza de emplearse, ha perdido su verdadera significación?», se pregunta la socialista Herminia Brumana ${ }^{22}$ (Herminia Brumana, mujer de recio temperamento..., 1929, p. 45). Ella, que no se considera escritora, sino una «modesta y simple trabajadora», o una «obrera» de la literatura, propone llamativamente el sentir como un valor legitimante: «No basta que a uno le digan o la llamen escritora por ahí los amigos o los admiradores. Hay que sentirse escritora, como no basta tener un hijo para ser realmente madre, o, por lo menos, para ser una madre digna» (p. 45) ${ }^{23}$. El sentimiento es performativo en Brumana y, por lo tanto, genera efectos políticos. La emoción no se opone a lo «pensado», al contrario, en su respuesta se construye material y maternalmente un «pensamiento corporizado» (Rosaldo en Ahmed, 2015, p. 258) que también reniega del genio y apuesta por el trabajo intelectual. Emoción, sentimiento, sensibilidad se ponen al servicio de la profesionalización de la escritora, aunque a la socialista no le guste la categoría, porque es un modo eficaz de configurar una identidad escrituraria como experiencia

21. Cfr. Altamirano y Sarlo (1997), Dalmaroni (2006).

22. Herminia Brumana (1901-1954). Escritora, periodista, dramaturga y activista argentina, de ideas socialistas y anarquistas. Escribió nueve libros, once obras de teatro, algunas estrenadas. Colaboró en El Hogar, La Nación, Mundo Argentino.

23. Las cursivas me pertenecen.

Feminismo/s 38, July 2021, 281-306 
de contacto: no hay una instancia de éxtasis, sino un vínculo que se va construyendo, un cuerpo a cuerpo con la textualidad. Herminia Brumana, Raquel Adler, Nydia Lamarque, María Velasco y Arias se reapropian, invierten y tornan operativa la herencia afectiva que se les adjudica en tanto «mujeres». Una nueva «nueva sensibilidad» de jóvenes escritoras que, no tan alejadas del gesto vanguardista, contra-leen su historia. Ahora bien, no debe confundirse este mecanismo del sentir con la opción por una literatura sentimental y femenina, aun cuando en algunas ocasiones estén equiparados.

No es el caso de Velasco y Arias que, en su reseña sobre la primera Antología de poesía femenina, si bien sostiene la necesidad de un elemento artístico asentado en el «sentimiento», desconfía del alto volumen de poesías que exaltan las «cualidades femeninas» de «suavidad, ternura, delicadeza» (1930, p. 123). Cuenta que hace un tiempo viene recortando las columnas impresas con referencia a escritoras y ese archivo personal arroja la conclusión de que, en general, ellas participan de artículos que tienen el estilo de un «diccionario enciclopédico elemental» que las acoge con «una facilidad rayana en desgobierno» (1930, p. 123). A diferencia de Raquel Adler, Velasco no confía en la variable numérica per se, que asocia a cierto paternalismo literario y periodístico que, «más solícito por la hermosura de la 'escritora' que por eso lo escrito, casi de continuo, inferior, que pergeñe, con inspiración de merenguista, media columna de acarameladas palabras» (1930, p. 123). Para esta escritora, hay una relación estrecha entre las convenciones frívolas de la moda y la feminidad que se traslada al campo literario sexualizado, por eso afirma que «no existe literatura de sexo ni sexo literario; me refiero a las letras desinteresadas, no a las didácticas. No hay literatura femenina ni masculina en el alcance biológico de los términos porque ni mujeres ni hombres son progenitores en tal sentido» (1931, p. 8). De nuevo, aparece esta necesidad de desvincular lo literario de lo fisiológico-maternal para así trasladar la disputa al plano de la cultura; y, desde ahí, Velasco también responde a las declaraciones machistas que Enrique de Gandía había realizado en la revista:

«¿Qué mujer ha osado medirse con Homero...?» El joven historiador olvida a la maestra de Píndaro, a la vehemente Safo, a Teresa de Cepeda, a la hispanamejicana Sor Juana Inés, a Gertrudis Gómez de Avellaneda, a Carolina Coronado, a la dulcísima sin par Rosalía, a la Ada Negri de la pobreza, 
quienes tragando hieles pudieron circular las mieles de sus espíritus combatidos por la sociedad puesta en guardia contra la mujer instruida y más aún contra la escritora. (1931, p. 9)

La genealogía le da una inscripción histórica a la tarea de la escritora. Y esta historia que se escribe es trasnacional, sincrónica, plural, azarosa, discontinua. Si Adler armaba comunidad de mujeres, María Velasco y Arias le da a esa comunidad una contra-memoria.

Gandía le había otorgado una entrevista a La Literatura Argentina dos meses antes, y ante la pregunta del reportero sobre la idea de Adler, de que la poesía debía ser cultivada exclusivamente por escritores del sexo femenino, este había replicado que «en ninguna época hubo una poetisa superior a ningún poeta de su tiempo. (Una entrevista con Enrique de Gandía, 1931, p. 340). También había observado que la literata, por su propia profesión, se masculinizaba. En diciembre de 1931, se publica la respuesta del escritor a María Velasco; pero antecedida por un recuadro de Adler que encuadra el texto dentro del movimiento femenino de la revista. Si, leemos, todo lo que puede estimular y analizar la obra de la mujer escritora debe ser meditado por las escritoras con conciencia, en la oración final se aclara: «Demás está decir que el movimiento femenino, que iniciamos en La Literatura Argentina, acompañará siempre con el estímulo y la justicia a todas las escritoras» (Gandía, 1931, p. 103). La voz masculina, por primera vez, está observada, rodeada, no fluye con libertad o impunidad por la página. Gandía repite algunos de los tópicos ya comentados, como la vanidad de la poetisa y su deseo de adueñarse del género poético, ahora bajo el rótulo de "partido 'feminista'» (p. 103). Se burla de la lista de escritoras que Velasco enumeró, especialmente de la mención a Safo, «la más insignificante de los poetas de su tiempo, a quien sin duda no ha leído ninguna de las damas que la citan» (p. 103). La argumentación «novedosa» se inscribe en el discurso psiquiátrico: el contendor analiza «la mentalidad de la poetisa» como una neurótica narcisista literaria y sexual. Al año siguiente sigue la polémica, Hilda Pina Shaw y Malvia Rosa Quiroga ${ }^{24}$

24. Hilda Pina Shaw (1910-). Escritora y periodista, secretaria de redacción de la revista Estampa. Publicó La influencia mística en Tolstoi, Esteban Echeverría: su nombre es una espada de libertad y libros de poesía. Malvia Rosa Quiroga (1900-1983). Maestra, poeta y escritora cordobesa, comienza su actividad literaria en 1925 con Mis rosas

Feminismo/s 38, July 2021, 281-306 
salen en defensa de Gandía, Velasco le responde en un largo artículo de tres páginas y seis puntos. Solo quiero, para terminar, citar este fragmento:

¿Insinceridad de las creadoras? Bueno; igual abstracto sustantivo cuadra a la labor masculina en varias docenas de veces; ¿estarían si no, vivos los autores? La real neurosis narcisista literaria, no es, por otra parte, enfermedad de señoras; el «gentil Narciso» fue varón... (1932, p. 139)

El razonamiento es impecable en su simpleza y contundencia, si a las mujeres se las excluye de la cultura, que los varones se hagan cargo de sus mitos y sus patrones de interpretación.

\section{CONCLUSIÓN}

En La Literatura Argentina las no autorizadas escriben y leen, se leen y debaten, se afirman autoras performando intervenciones variadas y creativas sobre un campo literario masculino que se organiza desde la diferencia sexual como valor. Si bien es evidente, como ha señalado Fletcher (1993), que una discriminación positiva se comprueba en la revista en relación con la creatividad femenina, también se encuentran zonas críticas que discuten las divisiones de género para pensar la literatura y problematizan los modos de acceso a la prensa y la edición.

El recorrido mostró los modos en que las escritoras confeccionaron un contra-archivo feminista como «poiesis de futuro» (Pollock, 2010, p. 11), es decir, como una posibilidad, un devenir que todavía no es real. Sus estrategias dieron cuenta de ello: nuevos recorridos, inversiones, expropiaciones y apropiaciones, reafirmaciones colectivas, cuestionamientos, genealogías propias. Además de las emociones que, también desde un movimiento contra-archivístico, o sea, contra-histórico, funcionaron como un sustrato compartido desde el que intervenir públicamente, hay otro gesto político que complementa y recorre todo este primer período de la publicación: la urgencia por una justicia socio-cultural, histórica y literaria que contemple las voces de mujeres. La Literatura Argentina es tanto un baúl que contiene las experiencias sexistas que atraviesa el ámbito literario nacional en los años

pálidas. Obtuvo el diploma en Filosofía en la Facultad de Filosofía y Humanidades de la Universidad Nacional de Córdoba, donde ejerció la docencia.

Feminismo/s 38, July 2021, 281-306 
veinte y treinta como un archivo testimonial de las formas de resistencia que activaron una comunidad de escritoras, y que inscribimos en la historia del feminismo latinoamericano.

\section{REFERENCIAS BIBLIOGRÁFICAS}

Abella Caprile, M. (1932). Una aclaración. La Literatura Argentina, 42, 183.

Adler, R. (1930a). Antología de poetisas argentinas, compilada por Maubé y Capdevielle. La Literatura Argentina, 26, 41.

Adler, R. (1930b). Conceptos sobre la nueva sensibilidad, que no se publicaron. La Literatura Argentina, 18, 167-168.

Adler, R. (1931a). Consideraciones sobre los premios femeninos - Formación de Jurados e institución de premios. La Literatura Argentina, 37, 10.

Adler, R. (1931b). Escritoras del interior. La Literatura Argentina, 38, 39.

Adler, R. (1931c). Las escritoras versus el Jurado Municipal. La Literatura Argentina, 34, 315-316.

Adler, R. (1933). A manera de respuesta (a Arturo Cancela). La Literatura Argentina, 58, 284.

Adler, R. (1936). De la tierra al cielo (Ensayos literarios). Editorial Serviam.

Agamben, G. (2002) Lo que queda de Auschwitz. El archivo y el testigo. Homo sacer III. Pre-textos.

Ahmed, S. (2015). La política cultural de las emociones. UNAM.

Altamirano, C. y Sarlo, B. (1997). Ensayos argentinos. De Sarmiento a la vanguardia. Ariel.

Barrancos, D. (2007). Mujeres en la sociedad argentina. Una historia de cinco siglos. Sudamericana.

Buceta, C. (1929). Clotilde C. Buceta no puede opinar sobre la producción literaria de 1928. La Literatura Argentina, 7, 11.

Chérie García y Onrubia. Vidriales. (1928). La Literatura Argentina, 2, 23.

Dalmaroni, M. (2006). Una república de las letras. Lugones, Rojas, Payró. Escritores argentinos y Estado. Beatriz Viterbo.

Dantas Lacombe, M. (1929). Libros femeninos del año 1928, juzgados por la Dra. Mercedes Dantas Lacombe. La Literatura Argentina, 5, 4.

El concurso literario del Club Argentino de Mujeres. (1929, septiembre). La Literatura Argentina, 13, 10.

Entrevista a Lucila De Gregorio Lavié: La nueva ley adolece de defectos. (1933). La Literatura Argentina, 62, 32. 
Exposición femenina del Libro Latino = americano. (1931). La Literatura Argentina, 36, 365.

Fletcher, L. (1993). El desierto que no es tal: escritoras y escritura. Feminaria, 11 (6), 7-13.

Foucault, M. (1992). Nietzsche, la genealogía, la historia. En J. Varela y F. Álvarez-Uría (Eds.), Microfísica del poder (pp. 7-30). La Piqueta.

Foucault, M. (1997). La arqueología del saber. Siglo XXI.

Gandía, E. (1931). La mujer y la poesía. La Literatura Argentina, 40, 103-5.

Guasch, A. M. (2011). Arte y archivo. 1920-2010. Genealogías, tipologías y discontinuidades. Akal.

Hablan para La Literatura Argentina todos los premiados y la única mujer votada en el concurso literario municipal, definiendo sus personalidades, sus juicios sobre el fallo y sus propósitos. (1929, junio). La Literatura Argentina, 10, 13-17.

Herminia Brumana, mujer de recio temperamento, quiere libros construidos con ideas y no con palabras. (1929, octubre). La Literatura Argentina, 14, 45-46.

La Literatura Argentina. (1928). La Literatura Argentina, 1, s.p.

Margarita E. Armasseva, En silencio. (1929, febrero). La Literatura Argentina, 6, 24.

Masiello, F. (1997). Entre civilización y barbarie. Mujeres, Nación y cultura literaria en la Argentina moderna. Beatriz Viterbo.

Méndez, M. (2017). Crónicas travestis. El periodismo transgresor de Alfonsina Storni, Clarice Lispector y María Moreno. Beatriz Viterbo.

Mosaico de Herminia C. Brumana. (1929, diciembre). La Literatura Argentina, $16,117$.

Notas femeninas (1931). La Literatura Argentina, 37, 26.

Pierini, M. (2006). La revista bibliográfica La Literatura Argentina (1928-1937). El Matadero. Revista crítica de literatura argentina, Segunda época, 4, 93-113. Pollock, G. (2010). Encuentros en el museo feminista virtual. Tiempo, espacio y archivo. Cátedra.

Pollock, G. (2013). Visión y diferencia. Feminismo, feminidad e historias del arte. Fiordo.

Raquel Adler presenta un panorama de la literatura argentina. (1929, octubre). La Literatura Argentina, 14, 36.

Storni, A. (2002). La mujer como novelista. En Muschietti, D. (Ed.), Obras. Narraciones, periodismo, ensayo, teatro (Tomo 2, pp. 982-983). Losada. 
Szurmuk, M.y Torre, C. (2018). Nuevos géneros, nuevas exploraciones de la condición de mujer: viajeras, periodistas y mujeres trabajadoras. Mora, 24, 191-202. https://doi.org/10.34096/mora.n24.6318

Telles, N. (2020). Retratos de mulher. Niterói, 2 (10), 19-46.

Una entrevista con Enrique de Gandía. (1931). La Literatura Argentina, 35, 340. Velasco y Arias, M. (1930). El primer cancionero dedicado a la poesía de la mujer argentina contemporánea. La Literatura Argentina, 28, 123.

Velasco y Arias, M. (1931). Entrevista. La Literatura Argentina, 37, 8-9.

Velasco y Arias, M. (1932). La mujer y la poesía. La Literatura Argentina, 41, 137-140.

Vicens, M. (2017). Ensayos profesionales: literatura, mujer y trabajo en la prensa porteña finisecular. Anclajes, 21, 77-94. https://doi.org/10.19137/ anclajes-2017-2125 